U.D.C. 622:330.15

keywords: lithosphere, biosphere, socioeconomic activity, mining and metal production enterprise

A. I. Tatarkin, A. I. Semyachkov

\title{
SOCIOECONOMIC AND ECOLOGICAL FUNCTIONS OF THE LITHOSPHERE
}

Interaction of the lithosphere and the biosphere with a view of socioeconomic activity by a human being has the most complete effect in the process of mineral resource utilization. It is typical of mining and metal production complexes (MMC) of the Ural, which are basic for the regional economy.

$A$ research methodology related to anthropogenic transformation of environment caused by MMCs, including techniques, principles of construction, forms, means and approaches to the scientific knowledge has been developed.

Functions of lithosphere (its upper layer) as a global system including anthropogenic and natural processes taking place within it are the principal lifesupporting functions determining development and existence of the modern society and the plant and animal life as a whole. The life-supporting functions of the lithosphere are considered in a number of joint works by V. T. Trofimov [3, 4]. The basic economic and ecological functions of lithosphere are given in fig. 1.

A socioeconomic (resource-based) function of the lithosphere includes the following aspects of geological environment, in opinion by V. T. Trofimov
[4]: mineral site (deposit), environmental space that determines development of the society, its economic activity and a process of anthropogenesis in the geological environment. The names of the aspects themselves indicate close interdependence between the economic activity by the human society and an economic entity, which implies geological space of an upper layer of the lithosphere and deposits that yield minerals.

11 large regions that possess strategic (national) minerals have been singled out on the basis of the search results and prospecting on the territory of the Russian Federation: Northern, North-Western, Central, Central-Black, North-Caucasian, Povolzhsky, Volgo-Vyatsky, Ural, West-Siberian, East-Siberian.

By present, allocation of basic mineral resources among the regions of the Russian Federation has been observed (Table 1).

According to the geological data, the explored oil reserves in Russia make up 12-13\% of the world reserves; gas - over $35 \%$ and coal $-12 \% .70 \%$ of all Russian reserves are due to fuel and energy resources and $30 \%$ are due to ore and non-metallic minerals.

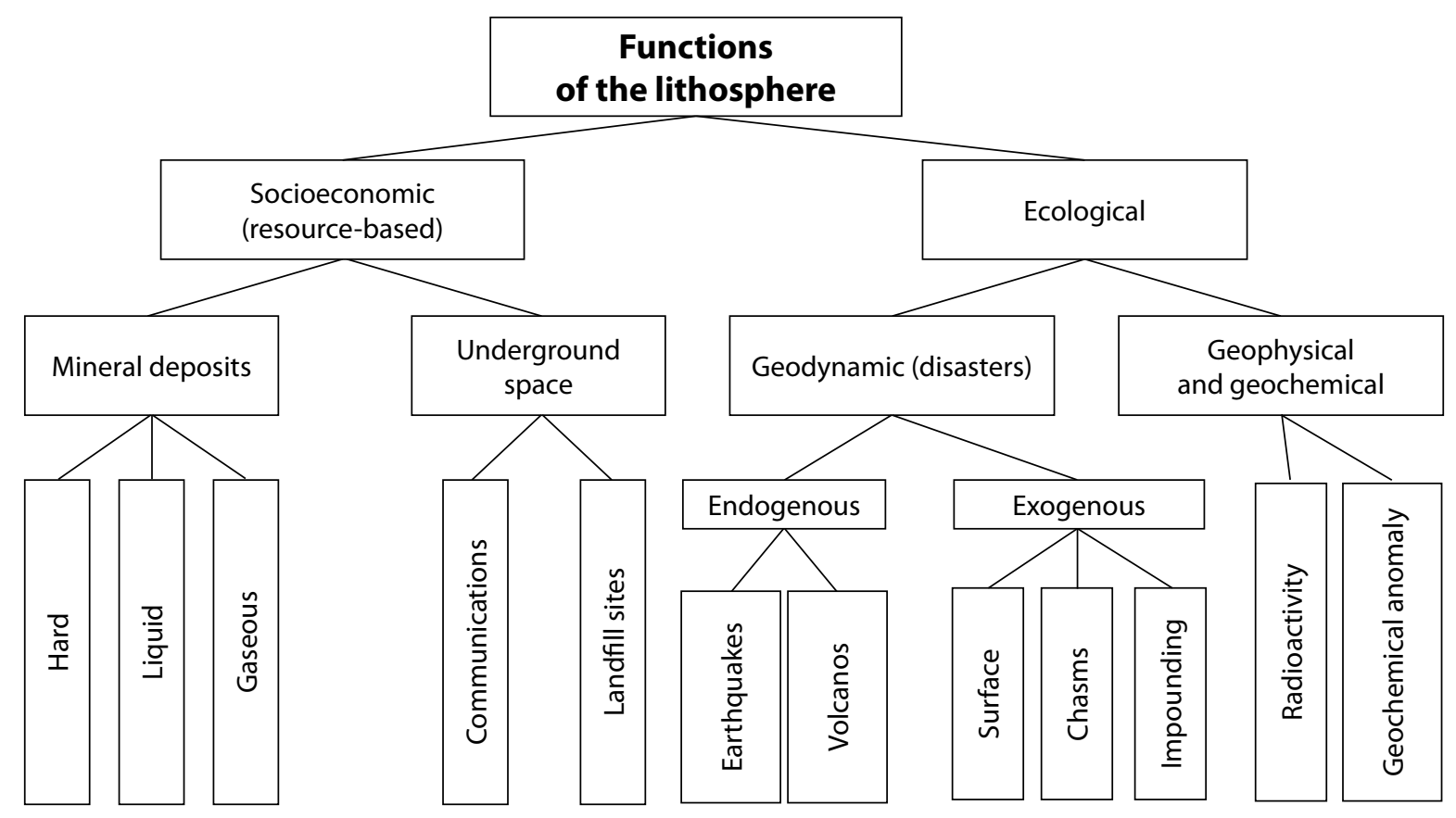

Fig.1. Functions of the lithosphere 
Table 1

Distributing of deposits of basic mineral resources of the Russian Federation

\begin{tabular}{|l|l|}
\hline Type of resources & \multicolumn{1}{|c|}{ Region } \\
\hline Oil and gas & $\begin{array}{l}\text { Khanty-Mansijsk Autonomous District, } \\
\text { Yamal-Nenets Autonomous District }\end{array}$ \\
\hline Coal & $\begin{array}{l}\text { Kemerovo region, Krasnoyarsk } \\
\text { Territory }\end{array}$ \\
\hline Zinc, lead, silver & $\begin{array}{l}\text { Krasnoyarsk Territory, Buryatiya, } \\
\text { Primorie Territory }\end{array}$ \\
\hline Gold & $\begin{array}{l}\text { Magadan region, Republic of Sakha } \\
\text { (Yakutia) }\end{array}$ \\
\hline Nickel & Krasnoyarsk Territory \\
\hline Tungsten & $\begin{array}{l}\text { Kabardino-Balkarian Republic, } \\
\text { Primorie Territory }\end{array}$ \\
\hline Copper & Kemerovo region \\
\hline Molybdenum & Krasnoyarsk Territory \\
\hline Tin & $\begin{array}{l}\text { Magadan region, Khabarovsk Territory, } \\
\text { Republic of Sakha (Yakutia) }\end{array}$ \\
\hline Bauxites & Sverdlovsk region, Arkhangelsk region \\
\hline Iron & $\begin{array}{l}\text { Belgorod region, Sverdlovsk region, } \\
\text { Kursk region }\end{array}$ \\
\hline Phosphorites & Murmansk region \\
\hline
\end{tabular}

Resource potential of a territory is closely related to the issues of utilization and protection of nature in a particular region and a particular component.

The socioeconomic function of the lithosphere is researched in two lines - superficial and hypogene. Thus, the superficial line includes researches concerned with sustainable utilization of landscapes - land resources, and the hypogene line consists in estimation of resources lying in the depths of geological assemblies, and sustainable utilization of both a resource itself and a space.

The function of the upper layer of the lithosphere plays a considerable role as a geological space used by the society for its existence. Thus, cities, settlements and technical systems are allocated on the land surface, major economic activities take place and the principal part of the biota lives - shrewing beings and microorganisms, and it is also utilized for technical purposes. Virtually all underground engineering services in modern cities are located in a geological environment. Underground garages, transport networks, subway, toxic chemical underground disposal sites, industrial wastewater, domestic and radioactive waste are constructed. By present, over $56 \%$ of the earth surface is developed by the society. Over 20 milliard tons of mined rock is annually withdrawn from the subsoil. A process of exhaustion of resources is in progress.

A geodynamic function of the lithosphere is set forth according to the point of view by V. T. Trofimov [3], who refer to the geodynamic function of the lithosphere as an ability of the latter to show and develop natural and anthropogenic geological processes and phenomena, which to a certain extent influence life conditions and vital functions of the biota and especially of the human society. Anthropogenic and natural geological processes and phenomena are a general geological force transforming the world around and influencing the organic system evolution. At present anthropogenic activity of the society in relation to the lithosphere is considered as one of the exogenous process factors, which do not yield to natural processes in terms of the impact on the environment.

According to the data by the UN, about $25 \%$ of the population of the Earth dwells on territories that are dangerous and geological-calamity-prone. The society learned to forecast natural calamities and it takes measures to reduce damage caused by them.

Presence of the geophysical and geochemical fields of natural and anthropogenic origin in the lithosphere has been established in the issue of the regional researches. It was until recently that geophysical and geochemical anomalies had been attributed to the presence of different minerals in the subsoil. The given minerals were recorded as geophysical anomalies by geophysical instruments, i. e. those minerals vary from the geophysical parameters of the environment. Geochemical anomalies related to the presence of mineral deposits in the subsoil were recorded on a day surface in a similar way. With the lapse of time researchers attributed such anomalies to the status of geopathogenic zones.

Some anomalies proceed to the atmosphere at an elemental level and negatively influence the biota in the environment. Therefore geophysical and geochemical anomalies (geopathogenic zones) are researched in terms of their impact on living organisms and plants. Geophysical and geochemical anomalies are subdivided into natural and artificial (anthropogenic).

Natural anomalies are an exploration target in the search for mineral deposits of pivotal elements. Thus, for instance, the boosted values of $\mathrm{Cu}, \mathrm{Zn}$, $\mathrm{Rb}, \mathrm{Sc}, \mathrm{Cd}, \mathrm{SO}_{2}, \mathrm{CO}_{2}$ etc. are analyzed above sulfide deposits. Conductors of harmful emanation are almost always cavities in rocks and tectonic abnormalities, which toxic chemical elements come to a day surface through. Deposits of uranium and kies $(\mathrm{Cu}, \mathrm{Ng}, \mathrm{Sb}, \mathrm{As}, \mathrm{Se}, \mathrm{Te}, \mathrm{Bi}$ etc.) are considered unsafe. Anthropogenic anomalies vary extremely in terms of their structure and scale of geological environment pollution. Such anomalies correspond to sources of technogenesis: industrial enterprises, agriculture, military-industrial complex and other 


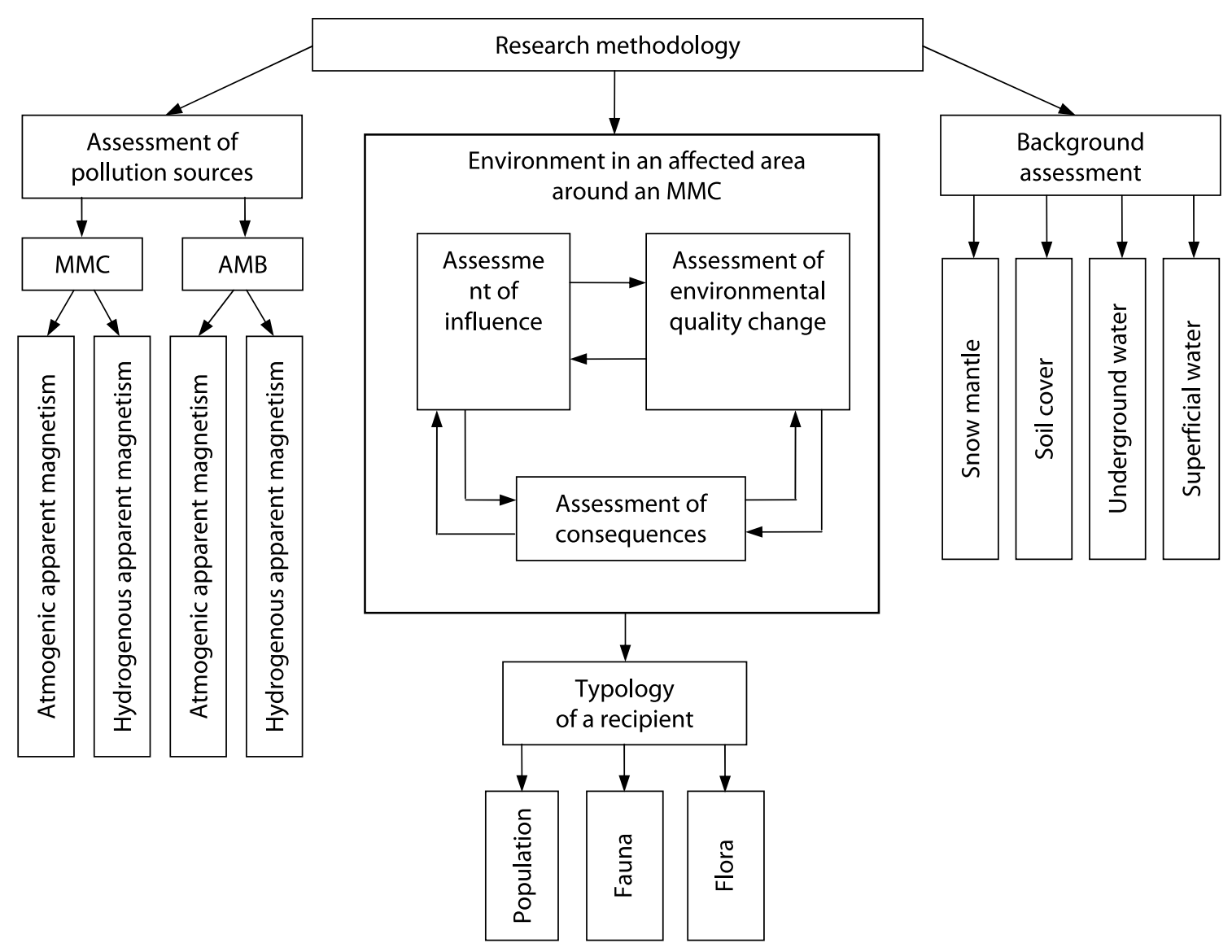

Fig. 2. Research methodology referred to anthropogenic environmental change and consequence generation (conventional signs: MMC — mining and metal complex, TME — anthropogenic mineral build-ups)

well-known anthropogenic anomalies - radioactive (Chernobyl, Chelyabinsk-67), hydrocarbon anomalies referred to the oil field, compressor systems, petrochemical and refining plants etc.

Interaction of the lithosphere and the biosphere with a view of socioeconomic activity by a human being has the most complete effect in the process of mineral resource utilization. It is typical of mining and metal production complexes (MMC) of the Ural, which are basic for the regional economy.

The developed research methodology related to anthropogenic transformation of environment caused by MMCs, including techniques, principles of construction, forms, means and approaches to scientific knowledge, determines a logical system of research shown in Figure 2.

Soil horizon and superficial water directly influence living organisms, maximum permissible concentration was developed according to theirvalues. The most essential constituents of the environment, under which consequences are generated, are vegetation and animals, and ecological condition of them determines human wellbeing (fig. 3).

As is generally known, major amount of pollutants $(75-85 \%)$ get into a human organism together with vegetable food. Polluted air or water have also direct influence on a human organism and that fact generates relevant consequences.

Pollutants that get into an organism cause grave diseases connected with reaction of such pollutants with a number of enzymes and suppression of activity of the latter. Dangerous nature of pollutants is specified by their ability to bio-accumulation, i. e. long-term accumulation and toxic concentration generation.

In less detail methodological recommendations concerned with revelation and typification of consequences of environmental pollution by heavy metals can be presented as follows:

1. Selection of an MMC as a subject of inquiry.

2. Substantiation of basic types of geological and ore structures and geochemical specialization of deads inherent to them, imposition of an MMC to belong to one of the revealed structures.

3. Assessment of background content of pollutants in a snow mantle, superficial water and soil horizon using geochemical techniques of sampling.

4. Description of anthropogenic influence manifested by pollution of environmental constituents that takes place in the process of development of subsoil resources in the context of 


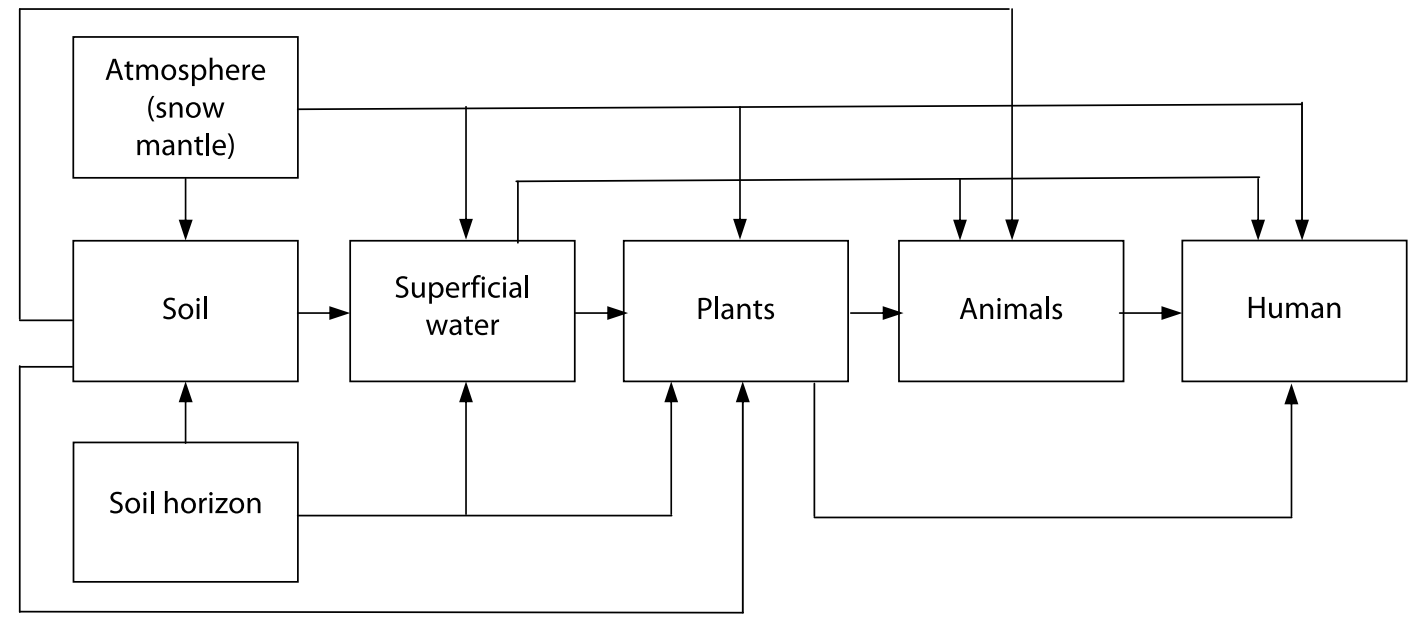

Fig. 3. Scheme of pollutant migration in copper-ore industry areas

the MMC investigation. Identification of the most significant influence by way of comparison of actual content of a certain element of heavy metals in a soil layer, snow mantle, superficial water with its background value.

5. Zonation of the area surrounding the MMC (pollution source) based on concentration of the most significant elements revealed in the snow mantle, soil, superficial water.

6. Identification of typical recipients on the territory under investigation, that are subject to the influence by the MMC: types and groups of plants and animals, fish individuals, mature population groups, specification of quantity regarding their condition (density of population, forest yield etc.).

7. Assessment of accumulated concentration of elements in plants, animals, fish individuals, human biosubstances (blood, urine, hair). Specification of correlation dependence between the content of elements in plants, animals, fish individuals, human beings and content of the same elements in the environment. Differentiation of correlation dependence for individual groups of investigated recipients taking into account their specific features.

8. Identification of consequences of element accumulation in plants, animal organisms, fish, human, that manifest in the form of a certain disease, physical malformation, fatal outcome, change at a genetic level. Identification of correlation dependence between a parameter of consequence generation probability within a certain group of recipients, and a pollution extent.

9. Assessment of economic damage in terms of influence on the environment by MMCs.

Quality of environment should not be referred to only as a degree of pollution but also a complex of socioeconomic, biological, chemical, physical, climatic and geographical conditions (factors) that generate external environment, which creates conditions for a human life.

The World Health Organization (WHO) refers to human environment as a complex of external physical, chemical, biological and social factors, which have an influence on health and wellbeing of both individuals and large groups of population.

The main means of prevention of human diseases that occur as a result of environmental factors' influence is ecological, not physiological, adaptation, i.e. control and regulation of chemical environment of a human. The process of ecological adaptation is related to generation of new ecological systems.

Space and time features referred to interaction of organisms with the environment within the biosphere occur in different social and natural and socioeconomic conditions, at the level of particular ecosystems and geosystems. A human as a part of this complex geosystem lives not only within the natural environment, but also within the anthropogenic, economic and cultural environments, and the ecosystem acquires its territorial expression. All environments surrounding a human are interdependent, they are differentiated and integrated. In point of fact the question is about complex geo-, eco- and sociosystems, in which a model of interrelation is presented as follows: human - nature - technology - economy - society - culture.

An emphasis within such systems is made now not only on protection and rehabilitation of the nature, but on creation of cultural, controlled, naturalanthropogenic landscapes and formation of an environment with the specified optimal ecological parameters. Sustainability of such landscapes improves due to their controllability by a human, and it is accomplished by conformity in structure 
and orientation of natural and socioeconomic subsystems.

A necessary condition for an ecosystem is consistency of the biota as a whole. It may be considered as a kind of a mechanism for preserving all the biocenosa constituting it.

A major principle of the biota organization aimed at increasing its stability and securing optimal conditions for life continuation is competitive interrelation of communities.

At the same time competitive interrelation of civilization subsystems is a major factor (in terms of several aspects) of the modern civilization instability.

Thus, natural and social subsystems are different in terms of, uppermost, mechanisms to secure stability.

From the functional point of view, a basis for a stabilization mechanism in reference to the biota is a memory of generation.

It is supplemented by a non-genetic memory (culture) if applied to the civilization as a superbiological structure.
Thus, development of geo-, eco- and sociosystems is to be accomplished within the scope of innovation processes and information technologies. The given scope is most applicable to the systemic renewal of the country and generation of a post-industrial society on the basis of economically reasonable technologies consistent with nature.

\section{References}

1. Semyachkov A. I., Ignatyeva M. N., Litvinova A. A. Identification and typology of consequences regarding influence on the environment by mining and metal complexes. Ekaterinburg: Institute of economics of the UB RAS. 2008. 90 p.

2. Yegorenkov L. I., Kochurov B. I. Geoekology: teaching aid. M. Finances and statistics, 2005. 320 p.

3. Trofimov V. T. Theory and methodology of ecological geology. M.: MSU, 1997. 368 p.

4. Trofimov V. T. Ecological functions of the lithosphere. M. : MSU, 2000. $432 \mathrm{p}$. 